\title{
POISED TO ADVOCATE: THE PEDAGOGY OF THE LIGHTNING TALK IN CHILD AND YOUTH CARE EDUCATION
}

\author{
Johanne Jean-Pierre, Sabrin Hassan, Asha Sturge, Kiaras Gharabaghi, \\ Megan Lewis, Jonathan Bailey, and Melanie Panitch
}

\begin{abstract}
Advocacy is an integral part of child and youth care workers' roles and a significant component of child and youth care politicized praxis and radical youth work. Drawing from the qualitative data of a mixed-methods study conducted in 2019 at a Canadian metropolitan university, this study seeks to unpack how the pedagogy of the lightning talk can foster advocacy skills to effectively and spontaneously speak out with and on behalf of children, youth, and families in everyday practice when an unforeseen systemic challenge or barrier arises. A purposive sample of 70 undergraduate students was recruited in two child and youth care courses, both of which required students to present a lightning talk. Participants completed an online questionnaire with closed-ended and open-ended questions in order to share their perspectives of the pedagogy of the lightning talk. The findings show that the lightning talk fosters twenty-first century and metacognitive skills and, most importantly, advocacy skills.
\end{abstract}

Keywords: pedagogy, lightning talk, oral presentations, advocacy, child and youth care, youth work

Johanne Jean-Pierre (corresponding author) is an Assistant Professor in the School of Child and Youth Care, Ryerson University, 350 Victoria St., Toronto, ON M5B 2K3.

Email: jjeanpierre@ ryerson.ca

Sabrin Hassan, Factor-Inwentash Faculty of Social Work, University of Toronto

Asha Sturge, School of Child and Youth Care, Ryerson University

Kiaras Gharabaghi, School of Child and Youth Care, Ryerson University

Megan Lewis, Canadian Roots Exchange (CRE), Toronto

Jonathan Bailey, The Faculty of Behavioural Sciences, Yorkville University

Melanie Panitch, Office of Social Innovation and School of Child and Youth Care, Ryerson University

Acknowledgement: We would like to acknowledge that this research project was funded by a Ryerson University Learning and Teaching Grant (2019). We thank all the participants for taking the time to share their insights. 
International Journal of Child, Youth and Family Studies (2020) 11(3): 108-125

Using a range of pedagogical approaches, human services faculty and instructors strive to foster crucial skills during preservice education that lead to compassionate interactions with service recipients, ethical discretionary judgement, and beneficial supervision, management, and policy decision-making. Using developmental-ecological and reeducational approaches (Derksen, 2010; Mann-Feder \& Litner, 2004), child and youth care professionals in educational, health, corrections, residential, and community settings accomplish a variety of context-dependent tasks with children, youth, and young adults in their life-spaces, including primary care, relational practice, life-skills training, discipline, recreational and therapeutic activities, and counselling on the go (Krueger, 2007; Maier, 1991).

Given this range of potential duties and roles, child and youth care faculty are compelled to create learning opportunities that cultivate versatility, a broad understanding of the systems that shape professional practice, and a capacity to respond effectively in the moment to unexpected circumstances. In fact, a number of teaching activities adopted in child and youth care programs have been examined empirically, such as international experiential learning programs (Bellefeuille et al., 2017; Bellefeuille \& McGrath, 2013); arts-based activities, such as self-portraiture (Bellefeuille et al., 2018) and mask-making (Lashewicz et al., 2014); and weekly journalling and discussions (McKamey, 2017). Moreover, several authors have argued for the potential benefits of various pedagogies, such as creative inquiry (Bellefeuille et al., 2014), case-based learning (Sanrud \& Ranahan, 2012), practice placement (Forkan \& McElwee, 2002), improved integration of theory and practice (VanderVen, 1993), as well as the contributions of Indigenous elders as guest teachers (Cooke-Dallin et al., 2000). Empirical studies of oral presentations have explored biases in peer assessments of presentations (Vahid, 2017), how personality and motivation influence the performance of presentations (Liang \& Kelsen, 2018), and how the use of technology can assist in developing presentation skills (Gwee \& Toh-Heng, 2015).

Students' learning experiences of the "lightning talk", and its use in fostering advocacy skills development, have received only limited attention in academic literature. Some authors have discussed a shorter form of oral presentation, the 30 to 60 second "elevator pitch", which is a compelling speech designed to sell a service or product (Cox \& Marris, 2011; Pagana, 2013; Simpson, 2016). Recently, the Three Minute Thesis (3MT) competition, a contest that challenges graduate students to synopsize their research project in 3 minutes has also been explored (Hu \& Liu, 2018), but not as a pedagogical tool for advocacy development. For the purpose of this paper, a lightning talk is defined as an oral presentation of 3 minutes on a particular subject, given without supporting materials like notes and PowerPoint slides, and without audience engagement. It thus simulates a practice context for which the practitioner has had no opportunity to plan or prepare. As a further component of the lightning talk, students are asked explicitly to use persuasive communication skills in order to advocate for a particular perspective, action, or narrative. Everyday practice in different settings may require "thinking on one's feet" or spontaneously articulating a compelling case to prevent a course of action that could negatively impact service- 
International Journal of Child, Youth and Family Studies (2020) 11(3): 108-125

users. We contend that the lightning talk can help foster the metacognitive and advocacy skills needed to respond to unforeseen systemic challenges in everyday practice. This article's purpose is to build upon the aforementioned literature by examining how the pedagogy of a lightning talk can foster the skills required to effectively advocate with and for children, youth, families, and communities. Using qualitative data from a mixed-methods research project conducted with Canadian undergraduate students, this research project's results illustrate how the lightning talk can consolidate aspiring child and youth care professionals' twenty-first century and metacognitive skills so that they will be poised to advocate effectively in everyday practice.

\section{Context}

\section{Advocacy}

The Standards for Practice of North American Child and Youth Care Professionals (Child and Youth Care Certification Board, 2017) establish as a principle the responsibility to advocate for the rights of children, youth, and families, and to support them in their efforts to advocate for themselves. Child and youth care practitioners also often draw on the principles stated in the United Nations Convention on the Rights of the Child (1989) to inform their practice. More recently, we have been encouraged by the Truth and Reconciliation Commission of Canada (2015) to teach the legacy of colonialism and residential schools, and to support Indigenous peoples' actions for decolonization and institutional change. In the context of cross-sectoral, everyday practice, we suggest that advocacy can be defined as the capacities (a) to speak out, argue, plead, and act to confront and eliminate institutional and social barriers with, and on-behalf of children, youth, and families to promote their rights and well-being; (b) to actively empower youth to advocate for themselves, which can involve meaningful participation in decision-making processes; and (c) to organize impactful plans and actions with and for youth and communities that uphold their collective aspirations for social change and equity. This tripartite definition implies that practitioners must develop an in-depth understanding of the social, economic, and political circumstances that affect their service recipients' regions and communities, and of the web of systems and regulations in which their organization of employment operates. Furthermore, it calls for the development of concrete skills that underpin effective advocacy in everyday practice as unexpected challenges emerge.

University-based child and youth care programs have sought to incorporate advocacy skills into their curricula, be that through dedicated courses (University of Victoria and Ryerson University), experiential learning (see Child and Youth Care Educational Accreditation Board of Canada, 2016; Keough, 2016), and community engagement activities at the local or international levels (Bellefeuille et al., 2017). However, such initiatives are rarely assessed in the context of supporting advocacy skills, and usually unfold without empirical evidence of their efficacy. In some fields, such as nursing, counselling, education, social work, and law, the development of knowledge and communication skills to empower future professionals to advocate on behalf of patients, students, or clients is accompanied by empirical research that aims to explore the impact 
of such initiatives on student capacity (Brawley, 1997; Doherty et al., 2016; Hurley, 2017; Nagro et al., 2019; Peltzer et al., 2016; Ramirez Stege et al., 2017; Vitielo, 2015). Such programs do so by designing and evaluating pedagogical tools across degree levels (bachelor, master, doctoral) that may involve experiential learning (Hurley, 2017; Peltzer et al., 2016); a formal communication competency program (Doherty et al., 2016); coursework, faculty projects, and internships (Anderson et al., 2005); or learning how to intervene through mass media with news releases, newspaper articles, letters to the editors, and radio and television interviews (Brawley, 1997). This list of pedagogical tools and their assessment in the aforementioned fields exemplifies how advocacy skills can be acquired in class and in the community concurrently or consecutively, and demonstrates that individual and group assignments furthering such skills can be designed and implemented. Advocacy is an integral part of North American child and youth care ethical guidelines and a cornerstone of critical youth work as politicized praxis. Pedagogical methods that further spontaneous advocacy skills on the part of students are therefore necessary if one is to perpetuate a strong ethical focus on critical, or radical youth work.

\section{Critical Youth Work, Radical Youth Work, and Child and Youth Care Politicized Praxis}

Critical youth work can contribute to empowering disenfranchised groups and initiating actions towards social change when policies, programs, and institutional decisions do not sufficiently consider the voices and ambitions of children, youth, families, and communities. Critical practice "is not an event, a final or ultimate moment of radical work, but a process of working towards a preferred, anti-oppressive future" (Bamber \& Murphy, 1999, p. 227). Critical youth work, or radical youth work, requires that we do not confine our role to engaging in recreational and therapeutic activities with children and youth, but that we form communities with youth to challenge oppressive structures and systems (Skott-Myhre, 2006). Effective advocacy buttresses critical youth work by centring the aspirations and voices of children, youth, and families, and by proposing alternatives to common or routine procedures and decision-making processes that can negatively affect their lives. While our role involves working towards greater equity and justice in the system on both the macro and micro levels (Gharabaghi \& Krueger, 2010), radical youth work can be challenging and uncomfortable because it involves examining one's own privilege and (in)visibility. It also requires that we question how we participate in the process of "othering" young people:

For many of us who live in centers of power and who hold certain privileges ascribed through race, class, socioeconomic status, gender, sexuality, or education, we have become accustomed to escaping scrutiny. We seldom have to account for our identity. We don't have to "come out" as heterosexual; we don't have to clarify, justify, or give testimony about our culture; account for our wealth and the behaviors associated with it (leaving aside the costs to others for our economic security); we don't have to defend our bodies against scrutiny or sexual assault. Our invisibility allows us to move through our society with a minimum amount of agreed upon surveillance. (Skott-Myhre, 2006, p. 226) 
International Journal of Child, Youth and Family Studies (2020) 11(3): 108-125

Akin to critical or radical youth work, Canadian professionals and scholars have proposed that we should embrace child and youth care as politicized praxis (Kouri, 2015; Loiselle et al., 2012). This idea stems from the praxis framework proposed by White (2007), where praxis is defined as a way of knowing, doing, and being, in which theory and practice intertwine to shape self-aware, ethical, responsive, and accountable practice. Politicized praxis is rooted in theories that challenge power differentials and advocate for actions driven by the desire for social change, such as critical race, feminist, queer, and postcolonial theories (Loiselle et al., 2012; Pon et al., 2011; Saraceno, 2012). Of equal importance are paradigms that name, confront, and propose holistic and pluralistic alternatives to Eurocentrism, such as Indigenous and Africentric worldviews (Asante, 2000; de Finney, 2015; Mazama, 2001; Simpson, 2014). Politicized praxis can involve planning and leading courageous conversations about Eurocentrism, Western cultural hegemony, and racism (Yoon, 2012); however, some child and youth care instructors have reported that students tend to avoid naming or addressing race and racism (Little \& Walker, 2012; McKamey, 2017). Other topics, such as colonialism, sexism, and the intersectionality of different forms of oppression, also provide an opportunity to unpack complex systems that perpetuate marginalization and "othering" (de Finney, 2015; de Finney et al., 2011; Saraceno, 2012; Skott-Myhre, 2006). Child and youth care politicized praxis literature is relevant to front-line work because critical work takes place daily when we create trusting and respectful relationships with youth while we share power and a meaningful purpose with them (Bamber \& Murphy, 1999). Advocacy in everyday practice can require practitioners to challenge actions that amplify macrostructural and exosystemic barriers, such as the discounting of youth and families' views, or the lack of procedural flexibility. Thus, course content and activities related to child and youth care politicized praxis delve into and move beyond the interpersonal dynamics and microdynamics of front-line relational practice, and tackle complex and evolving macrostructural and exosystemic factors through the continual questioning of power, privilege, and equity (Saraceno, 2012; Yoon, 2012).

If we lose sight of the reality that critical practice is an intentional, dynamic, and fluid process that aims to confront institutional barriers, historically rooted inequities, and oppression, we run the risk that we will become content - that we will "congratulate ourselves on our inclusive environments and our politically correct terminology yet cease to evolve beyond it" (Little \& Walker, 2012, p. 325). Child and youth care politicized praxis entails that we disrupt the individual-based, pathology-diagnosis-treatment linear model that aims to change youth, and focus on working with youth to change the social and institutional constraints that undermine their agency, human rights, and well-being (de Finney et al., 2012; Gharabaghi, 2014). While politicized praxis requires a grasp of critical theories and paradigms, an inclination toward inquiry and reflexivity, and a commitment to undertake concrete actions and interventions for social change, it also requires the capacity to speak up in the moment. In short, politicized praxis, aside from its theoretical and substantive contexts, includes spontaneously but assertively advocating alongside children, youth, families, and communities. This, commensurate with the skills underpinning the pedagogy of a lightning talk for effective advocacy, overlaps with twenty-first century and metacognitive skills. 
International Journal of Child, Youth and Family Studies (2020) 11(3): 108-125

\section{Twenty-First Century and Metacognitive Skills}

Some authors have suggested that a number of traditional pedagogies have emphasized the transmission of knowledge at the expense of fostering crucial competencies, such as creativity or problem-solving skills, that are deemed necessary to face contemporary life (Larson \& Miller, 2011; Tindowen et al., 2017). Globalization, economic fluctuations, technological development, and declining civic engagement engender the necessity for instructors to foster the skills needed to be successful in a range of circumstances and experiences (Kim et al., 2019). The term "twentyfirst century skills" is applied to those high-priority skills and attributes believed to be the most important to help students learn, live, and work successfully in the twenty-first century (Larson \& Miller, 2011). Although these skills may not be themselves new, they prepare individuals to locate and grasp information from multiple sources and subsequently apply it for decision-making purposes or innovation (Larson \& Miller, 2011; Tindowen et al., 2017). Twenty-first century skills encompass competencies such as critical thinking, problem-solving, creativity, metacognition, communication, civic responsibility, and global awareness (Kim et al., 2019; Saavedra \& Opfer, 2012), not merely as sequential or cumulative skills but as a fully integrated skill set, with due recognition of their intersectional character. Among these skills, metacognition is decisive to bolster the development of competencies, particularly the critical thinking skills that schools and

post-secondary institutions strive to inculcate. We contend that twenty-first century skills contribute to the ability to "think on one's feet" in everyday practice and spontaneously speak with and on behalf of service users who may face unexpected systemic barriers.

Metacognition takes place when individuals are aware of their thoughts, values, and feelings, and choose to mobilize this information to direct their learning (Kozikoğlu, 2019). In education, critical thinking enhances meaningful learning, and it is understood as the process in which students utilize existing knowledge to work through and solve challenges and problems (Magno, 2010). To engage in appropriate critical thinking, one must utilize metacognitive skills, such as the constant appraisal of thoughts and intentional efforts to progress towards a specific goal (Kozikoğlu, 2019; Magno, 2010). Metacognition can be regarded as having two components, both of which are crucial for effective learning: knowledge of cognition and regulation of cognition (Sperling et al., 2010). Knowledge of cognition involves knowledge of one's own cognitive processes (Sperling et al., 2010), while regulation of cognition is the mobilization of specific skills to control one's learning, such as planning, monitoring, and evaluation (Sperling et al., 2010). Without these twenty-first century and metacognitive competencies, it can be challenging to advocate effectively, particularly when we hope to reshape the decisions, actions, and narratives that may have a negative impact on children, families, and communities.

\section{Methodology}

This article draws from the qualitative data of a mixed-methods research design that used a post-test online questionnaire with both closed-ended and open-ended questions. The questionnaire included closed-ended questions with a Likert scale ("strongly agree" to "strongly 
disagree") pertaining to preparation strategies and learning processes involved in oral presentations, along with accessibility-related questions. There were some open-ended questions such as: "What would be useful for you to be better prepared for lightning talks, both at school and in the field?", and "What have you learned about your own strengths, interests, and ideas?" In this paper, we focus on qualitative data to explore students' rationales for and interpretations of how the pedagogy of the lightning talk can support the development of everyday practice advocacy skills.

This research project was conducted in April 2019 in two undergraduate child and youth care courses at a Canadian metropolitan university. Both courses required students to complete a lightning talk, defined as a three-minute oral presentation without the use of PowerPoint, notes, or any other such aid. We believe that preventing the use of notes and presentational aids is important because in everyday practice, practitioners will often be required to organize their thoughts quickly and argue clearly and concisely with and on behalf of children and youth. Advocacy accomplished by everyday front-line practitioners is as critical, meaningful, and valuable as organized and institutionalized advocacy, because it can transform children's life trajectories. In addition, the instructors aimed to reinforce core curriculum competencies, such as critical thinking, selfawareness, advocacy, and oral communication skills. One of the courses required that students define child and youth care work or an allied human services profession, present their own individual skills, and explain how they could contribute to enhancing the school climate. In the other course, students were expected to summarize a peer-reviewed article and make a compelling case about its relevance in order to encourage students to read and analyse its contents.

A purposive sample was employed, as only students registered in the two courses could complete the online questionnaire. A total of 70 undergraduate students completed the questionnaire. For the purposes of analysis, inductive coding was used to identify and explore the salient themes that emerged. Two research assistants conducted the analysis with the principal investigator to achieve triangulation and enhance methodological rigour (Bamberger et al., 2012). The qualitative software NVivo was used to analyse the data with three phases of coding. The first phase involved initial coding, in which each author compared the content of the respondents' narratives and remained open to different interpretations (Saldaña, 2016). The second phase involved pattern coding, in which we attempted to create categories and subcategories that summarized the various codes created from the first phase (Saldaña, 2016). The third phase involved axial coding to establish the connections between the categories and subcategories in order to remove redundant codes and merge similar codes (Saldaña, 2016). We obtained institutional ethics review board approval from a Canadian university for this study.

\section{Findings}

We recruited a total of 70 participants, and some skipped a number of questions on the online questionnaire. Nevertheless, $89.07 \%$ of the 64 participants who answered a closed-ended question 
International Journal of Child, Youth and Family Studies (2020) 11(3): 108-125

about their perceptions of the lightning talk indicated that they agreed or strongly agreed that the lightning talk promotes advocacy-related skills. The focus of the analysis below is on the qualitative data of this mixed-methods study, which seeks to unpack students' perspectives on the learning process.

The qualitative data discussed in this article is derived from the statements of the 48 of 70 participants who answered the following open-ended question: What have you learned about your own strengths, interests, and ideas? Only one of the 48 participants reported not having learned anything new. The remaining participants' narratives reflected the realization or improvement of communication and metacognitive skills that are instrumental for effective spontaneous advocacy and that overlap with twenty-first century skills. Participants' responses pointed to four main themes related to their learning experience: (1) the self-assessment of their public speaking skills, (2) the identification of self-regulation strategies, (3) the evaluation of their state of preparedness, and (4) the realization of the importance of advocacy skills.

\section{Self-Assessment of Public Speaking Skills}

The most salient theme captures how participants evaluated their capacity to accomplish the lightning talk without notes, PowerPoint slides, or other technological support. In general, respondents characterized their own public speaking abilities across a spectrum that ranged from "not so good" to "having confidence". Some students self-assessed that they were not proficient in public speaking. For instance, Perry wrote, "I'm awful standing in front of people, and would rather write a paper or speech." Similarly, Fabian realized that the lightning talk was more challenging than previously assumed: "I am a little worse at public speaking than I thought." Other students did not characterize their lightning talk presentation in negative or positive terms, but rather with nuance; they reflected upon the contexts or circumstances that could affect their effectiveness in speaking publicly. Nicky shared that the ability to speak publicly can be affected by the composition of the audience: "In front of my peers, I am horrible at public speaking. In front of strangers, I have no problem." On the other hand, Jaylen pointed to a difference in proficiency contingent on the type of oral communication activity: "I am better at spontaneous communication than presenting a speech."

Another group of students described a moment of self-actualization in which they acknowledged their own strengths and abilities. Noel stated, "I am good at presenting in front of the class." Like Noel, Angel recognized having the ability to speak in public after the lightning talk: "I learned that I am okay speaking in public." Florian uncovered an ability to improvise a lightning talk: "That I am pretty good with improvising in the moment." Along with greater knowledge of their competencies, the lightning talk yielded feelings of affirmation or increased self-confidence. For instance, Winter wrote, "I can do it!" For Val, being able to convey an idea in a compelling manner constituted an occasion of positive self-discovery: "That I have the ability to speak with conviction." Raven chronicled the metacognitive skills that contributed to the ability to speak publicly, and analysed her own thought process in the context of other students' 
International Journal of Child, Youth and Family Studies (2020) 11(3): 108-125

presentations: "My strengths are memorization and looking at things critically. I noticed I had a completely different idea from what others did." Rumi pinpointed that being passionate about a topic facilitated the task: "I can present easily about topics I'm passionate about." The ability to reflect on one's strengths and liabilities as a communicator constitutes a metacognitive skill that is valuable for engaging in advocacy and for self-regulation.

\section{Self-Regulation}

The second theme relates to the self-regulation strategies participants used to grapple with the stress associated with public speaking before and during the lightning talk. Responses indicated that self-motivation and self-encouragement constitute primary coping mechanisms. Some participants shared the motivational phrases that they used before and during their presentation. Landry wrote, as a cautionary note to future cohorts, "Don't second guess yourself." Similarly, Andy suggested, "Fake it until you make it." Halo articulated some inspirational thoughts that could nurture self-confidence before and during a lightning talk:

I am capable of anything. If you train your mind to believe in yourself, you can't fail. Lifting yourself by saying you got this and just being confident in your abilities goes a long way. You don't need to memorize a script. Be yourself.

These hopeful and supportive ideas may have helped some participants manage their emotions and nervousness while focusing on the task at hand. Some respondents' comments revealed how their ability to cope with stress or pressure influenced their ability to complete the lightning talk with confidence. Before the presentation, stage fright can cause some nervousness; as Haven explained, "I was more nervous before going up in front of the class than I was when I was actually up there." Despite their preparation for the lightning talk, some participants experienced high levels of stress that they felt impaired their ability to speak publicly. Marley shared, "I can memorize but get stressed under pressure." After the presentation, some respondents realized that their self-regulation strategies enabled them to face the pressure. Emery stated, "I am capable of completing a presentation under pressure." While the self-regulation of thoughts and emotions was significant, another factor was the students' self-assessed degree of readiness to carry out a brief oral presentation of three minutes without any form of written or technological support.

\section{State of Preparedness}

With regard to the third theme, the respondents suggested that an interest in the topic discussed, combined with certain metacognitive skills, resulted in the ability to successfully complete the lightning talk. Accordingly, in participants' narratives, memorization was strongly associated with being able to complete the lightning talk. For instance, Sparrow disclosed, "I am not good at memorizing texts." Wren attributed the ease of the presentation to practice and organizational skills: "With practice, I am able to be prepared and organized." Mirroring Wren's assurance, Avery stated, "I believe that I prepare effectively for presentations with my organization." Well-prepared students could utilize organizational and time management skills to fully comprehend and 
prioritize the content of their presentations. Consequently, Dallas observed that mastering a presentation's content can ease the challenge of public speaking: "Presentations are not difficult if you know your material." In addition to recognizing the benefits of being well-versed about a subject matter for the lightning talk, some participants remarked that they experienced fewer difficulties with public speaking when they had an affinity for the topic and were motivated to delve into its details. Robin wrote, "I liked the content of the presentation." Meanwhile, Parker discovered new academic inclinations: "I am very data driven and like exploring discussions surrounding discourses." Being prepared, organized, capable of prioritizing information, and having confidence reflect twenty-first century and metacognitive skills. Participants' responses illustrate how those skills can support advocacy in action.

\section{Capacity to Advocate}

The fourth theme encompasses respondents' statements relating to what they learned about their capacity to advocate both for children and youth and their professional roles. The child and youth care profession is sometimes mistaken for social work or early childhood education. In one of the courses, the lightning talk focused on introducing child and youth care professionals' specific roles, attributes, and singular contributions. As a result of the lightning talk, participants like Jean realized the importance of learning how to advocate: "I learned how it is important to think about how you would communicate your role as a CYC [practitioner] in a school." Others concluded that they felt ready to advocate for the profession. Emerald said, "I learned that I can advocate for child and youth care practices and values." Parallel to Emerald, Drew stated, "I am able to advocate for our profession." In the field, practitioners may face circumstances and situations on a daily basis that demand that they advocate for children, youth, families, and communities, in order to remove barriers to meaningful participation, empowerment, rights, and well-being. It is important that all aspiring child and youth care professionals develop the knowledge base and skill set to affirm with confidence, like Paris, "I have the ability to advocate for children and youth."

\section{Discussion}

In the discussion, we will initially focus on providing a synthesis of the findings. We will then tie our findings to a brief discussion on advocacy and its relationship to the lightning talk, reflecting the emphasis on building spontaneous speaking and response skills for practitioners. The results indicate that, for a number of undergraduate students, the lightning talk can be a challenging assignment due to limited communication, self-regulation, organizational, or metacognitive skills, which can result in a lack of self-confidence. Yet a majority of students expressed that they gained insights about their cognitive, public speaking, and interpersonal abilities,; fulfilled their potential; and improved their skills.

The results also indicate that students with self-awareness skills were less nervous about sharing their thoughts and views, and thus were better prepared and more confident for their 
lightning talk. These students were able to transition their thoughts from an apprehensive state into one of affirmation regarding their capacity to speak publicly. They were able to overcome their fear of presenting, recognizing that through previous learning opportunities they had gained competencies that prepared them to complete the lightning talk successfully. As advocacy skills are a core element of effective child and youth care practice, it is also important for practitioners to be confident in their ability to advocate. The process of preparing, presenting, and subsequently reflecting on the lightning talk enabled students to establish how effective they were at this skill, to recognize what they had achieved, and to become aware of areas that could be improved. It also helped strengthen their assurance in their ability to be successful as an advocate, as they were able to identify how their comfort level in completing this assignment demonstrated their ability to work well under pressure while expressing their idea clearly and effectively.

Some faculty may surmise that a certain proportion of human services professionals cannot be expected to develop oral communication skills due to shyness, overwhelming nervousness, or lack of interest in future advocacy or policy-related positions. Yet, "without adequate communication skills to address concerns, advocacy is threatened" (Doherty et al., 2016, p. 254). Other faculty may suggest that advocacy can be accomplished with actions such as writing an essay that do not involve public speaking. However, writing even a compelling essay may not be a suitable response when there is little time to prepare or organize; in an immediate crisis or dilemma, appropriately timed advocacy efforts are critical to successful intervention. When practitioners engage in frontline work, situations arise that require the clear and concise articulation of a problem, and an outline of how a solution could be achieved, by means of spontaneous public speaking. Pedagogical tools must be designed to promote intentionally advocacy-related skills, since advocating for children, youth, and families is an integral principle of the Standards for Practice of North American Child and Youth Care Professionals (Child and Youth Care Certification Board, 2017), and because child and youth care workers are often compelled to confront institutional and systemic barriers when engaging in politicized praxis or radical youth work. While a critical theoretical foundation can shape an understanding of actions that result in social change, the findings reveal that it is also important to develop certain practical skills to enact spontaneously politicized praxis in everyday front-line work. Combined with a critical curriculum and other pedagogical approaches, the lightning talk can contribute to preparing future practitioners to engage in child and youth care politicized praxis, and instructors can scaffold this approach throughout their program. In short, a politicized praxis in this field requires pedagogical tools that equip students with the skills and attitudes (like confidence and conviction) to challenge, resist, and offer alternatives to problematic and oppressive contexts at the micro and macro levels.

Based on the findings from the analysis of the qualitative data collected for this research project, we can state that: (a) students can learn with practice to achieve greater skill and confidence in spontaneous advocacy efforts; and (b) many students approached the prospect of speaking publicly without notes with trepidation, suggesting a need for pedagogic approaches designed to mitigate such fears and discomforts. 
International Journal of Child, Youth and Family Studies (2020) 11(3): 108-125

\section{Conclusion}

Following the completion of the lightning talk, the responses of undergraduate students attest that the lightning talk as a pedagogy can facilitate the development of twenty-first century and metacognitive skills that also constitute crucial advocacy skills in human services, particularly in child and youth care. More specifically, participants self-assessed their public speaking skills, reflected upon their ability to regulate their emotions, evaluated their state of preparedness, and realized the importance of advocacy capability. This research project contributes to the state of knowledge in child and youth care education in regard to the development of advocacy skills to sustain effective everyday critical youth work. In addition, this article emphasizes the importance of fulfilling the professional ethical principle to speak up, and the relevance of centring students' perspectives of their learning in our field. The results also suggest that, in other university programs, the lightning talk could be used to cultivate twenty-first century, metacognitive, and communication skills. Meanwhile, future studies can examine how university programs can scaffold the pedagogy of a lightning talk at different professional development stages, and for students with a range of public speaking and self-regulation abilities. For instance, for beginners, one possibility could be to scaffold the learning process by asking students to present for thirty seconds at first, then gradually increasing the length of the presentation to three minutes. More advanced pedagogical tools to develop capacity for advocacy might eliminate not only the use of supporting tools in oral presentations, but perhaps even the opportunity to prepare the topic itself: after all, practitioners are most in need of being able to "think on their feet" when they encounter unexpected situations in their practice. Advocacy is vital to politicized and ethical practice as a way of countering the silencing of young people, their families, and their communities. Other pedagogies that aim to encourage the development of advocacy skills should also be assessed empirically in light of students' perspectives on their learning.

Advocacy is ultimately a skill that we hope to do with, for, and on behalf of the children, youth, families, and communities whom we serve. Across the bachelor's, master's, and doctoral degree programs in child and youth care and youth work, faculty and instructors should regard, as a core component of their programs, the design and implementation of applicable pedagogies that scaffold and develop advocacy skills with individual, group, and community outreach activities. Based on students' perspectives in this study, the lightning talk can become one of the pedagogies used in conjunction with child and youth care praxis and radical youth work. Child and youth care and human services graduates not only need a strong grasp of the historical, social, political, and economic contexts of service recipients; and the ability to plan, network, and collaborate to achieve social change; but should also develop the required concrete skills to be poised to advocate when the need arises. 
International Journal of Child, Youth and Family Studies (2020) 11(3): 108-125

\section{References}

Anderson, E. A., Braun, B., \& Walker, S. K. (2005). Teaching family policy: Advocacy skills education. Marriage \& Family Review, 38(2), 61-76. doi:10.1300/J002v38n02_05h

Asante, M. K. (2000). Afrocentricity and history: Mediating the meaning of culture in Western society. Souls: A Critical Journal of Black Politics, Culture, and Society, 2(3), 50-62. doi:10.1080/10999940009362225

Bamber, J., \& Murphy, H. (1999). Youth work: The possibilities for critical practice. Journal of Youth Studies, 2(2), 227-242. doi:10.1080/13676261.1999.10593037

Bamberger, M., Rugh, J., \& Mabry, L. (2012). RealWorld evaluation: working under budget, time, data, and political constraints (2nd Ed.). Sage.

Bellefeuille, G., Crazyboy, L., Dela Cruz, J., Gladue, A., \& Walper, H. (2018). A qualitative inquiry in to the impact of an arts-based, self-portrait assignment on third year child and youth care students. Research Journal of Education, 4(3), 36-43.

Bellefeuille, G., Dalton, K. H., Neuman, S., Ammouneh, A., Anthony, C., Bautista, M., Benzon, G., Deol, J., Smith, L., Reid, K-A., \& Thang, S. (2017). Traversing the threshold in child and youth care education: A qualitative inquiry into the meaning-making experience of student participants in an international study tour. Research Journal of Education, 3(2), 12-22.

Bellefeuille, G., Ekdhal, C., Kent, L., \& Kluczny, M. (2014). A course-based creative inquiry approach to teaching introductory research methods in child and youth care undergraduate education. International Journal of Teaching and Education, 2(2), 1-9.

Bellefeuille, G., \& McGrath, J. (2013). A relational-centred international education partnership: A phenomenological inquiry into the lived experiences of child and youth care/social care students and faculty. Contemporary Issues in Education Research, 6(3), 279-288. doi:10.19030/cier.v6i3.7897

Brawley, A. B. (1997). Teaching social work students to use advocacy skills through the mass media. Journal of Social Work Education, 33(3), 445-460. doi:10.1080/10437797.1997.10778885

Child and Youth Care Certification Board. (2017). Standards for practice of North American child and youth care professionals. https://www.acycp.org/images/pdfs/ethics_and_practices_ACYCP_v2-1.pdf

Child and Youth Care Educational Accreditation Board of Canada. (2016). A preliminary investigation into field work models in Canadian child and youth care education. A report of the Child and Youth Care Accreditation Board of Canada. https://cycaccreditation.ca/wpcontent/uploads/2019/09/FWM.pdf 
International Journal of Child, Youth and Family Studies (2020) 11(3): 108-125

Cooke-Dallin, B., Rosborough, T., \& Underwood, L. (2000). The role of elders in child and youth care education. Canadian Journal of Native Education, 24(2), 82-91.

Cox, A. M., \& Marris, L. (2011). Introducing elevator speeches into the curriculum. Journal of Education for Library and Information Science, 52(2), 133-141.

De Finney, S. (2015). Playing Indian and other settler stories: Disrupting Western narratives of Indigenous girlhood. Continuum, 29(2), 169-181. doi:10.1080/10304312.2015.1022940

De Finney, S., Cole Little, J.N., Skott-Myhre, H., \& Gharabaghi, K. (2012). Conversations on conversing in child and youth care [Pre-Conference roundtable discussion]. International Journal of Child, Youth and Family Studies, 1(2-3), 128-145. doi:10.18357/ijcyfs32$\underline{3201210862}$

De Finney, S., Dean, M., Loiselle, E., \& Saraceno, J. (2011). All children are equal, but some are more equal than others: Minoritization, structural inequities, and social justice praxis in residential care. International Journal of Child, Youth and Family Studies, 2(3-4), 361-384. doi:10.18357/ijcyfs23/420117756

Derksen, T. (2010). The influence of ecological theory in child and youth care: A review of the literature. International Journal of Child, Youth and Family Studies, 1(3-4), 326-339. doi:10.18357/ijcyfs13/420102091

Doherty, C., Landry, H., Pate, B., \& Reid, H. (2016). Impact of communication competency training on nursing students' self-advocacy skills. Nurse Educator, 41(5), 252-255. doi:10.1097/NNE.0000000000000274

Forkan, C., \& McElwee, N. C. (2002). Practice placements: A cornerstone for child and youth care training. Child and Youth Care Forum, 31(6), 381-396. doi:10.1023/A:1021106316210

Gharabaghi, K. (2014). The purpose of youth work. In K. Gharabaghi, H. A. Skott-Myhre, \& M. Krueger (Eds.), With children and youth: Emerging theories and practices in child and youth care work (pp. 3-24). Wilfrid Laurier University Press.

Gharabaghi, K., \& Krueger, M. (2010). A new politic in child and youth care. Relational Child and Youth Care Practice, 23(3), 27-39.

Gwee, S., \& Toh-Heng, H. L. (2015). Developing student oral presentation skills with the help of mobile devices. International Journal of Mobile and Blended Learning, 7(4), 38-56. doi:10.4018/IJMBL.2015100103

Hu, G., \& Liu, Y. (2018). Three minute thesis presentations as an academic genre: A crossdisciplinary study of genre moves. Journal of English for Academic Purposes, 35, 16-30. doi:10.1016/j.jeap.2018.06.004 
International Journal of Child, Youth and Family Studies (2020) 11(3): 108-125

Hurley, K. S. (2017). Cheerleading practice: Community outreach for advocacy skill development. Strategies: A Journal for Physical and Sport Educators, 30(January/February), 47-49. doi:10.1080/08924562.2017.1253372

Keough, M. (2016). Practicum education in child and youth care [Master's thesis, University of Victoria]. https://cycaccreditation.ca/wp-content/uploads/2019/05/PracEd.pdf

Kim, S., Raza, M., \& Seidman, E. (2019). Improving 21st-century teaching skills: The key to effective 21st-century learners. Research in Comparative and International Education, 4(1), 99-117. doi:10.1177/1745499919829214

Kouri, S. (2015). The canonical self and politicized praxis: A tracing of two concepts. International Journal of Child, Youth and Family Studies, 6(4), 595-621. $\underline{\text { doi:10.18357/ijcyfs.64201514290 }}$

Kozikoğlu, I. (2019). Investigating critical thinking in prospective teachers: Metacognitive skills, problem solving and academic self efficacy. Journal of Social Studies Education Research, 111-130.

Krueger, M. (2007). Four areas of support for child and youth care workers. Families in Society: The Journal of Contemporary Social Services, 88(2), 233-240. doi:10.1606/1044-3894.3621

Larson, L. C., \& Miller, T. N. (2011). 21st Century skills: Prepare students for the future. Kappa Delta Pi Record, 121-123. doi:10.1080/00228958.2011.10516575

Lashewicz, B., McGrath, J., \& Smyth, M. (2014). Mask making in human services education: A case for student engagement. Journal of Teaching in Social Work, 34(2), 182-198. doi:10.1080/08841233.2014.897298

Liang, H.-Y., \& Kelsen, B. (2018). Influence of personality and motivation on oral presentation performance. Journal of Psycholinguistic Research, 47(4), 755-776. doi:10.1007/s10936$\underline{017-9551-6}$

Little, J. N., \& Walker, M. (2012). Reconceptualizing multicultural discourse as shifting geographies. Child and Youth Services, 33(3-4), 317-328.

doi:10.1080/0145935X.2012.745781

Loiselle, E., de Finney, S., Khanna, N., \& Corcoran, R. (2012). "We need to talk about it!":

Doing CYC as politicized praxis. Child and Youth Services, 33(3-4), 178-205. doi:10.1080/0145935X.2012.745778

Magno, C. (2010). The role of metacognitive skills in developing critical thinking. Metacognition Learning, 5(2), 137-156. doi:10.1007/s11409-010-9054-4 
International Journal of Child, Youth and Family Studies (2020) 11(3): 108-125

Maier, H. W. (1991). An exploration of the substance of child and youth care practice. Child and Youth Care Forum, 20(6), 393-411. doi:10.1007/BF00757498

Mazama, A. (2001). The Afrocentric paradigm: Contours and definitions. Journal of Black Studies, 31(4), 387-405. doi:10.1177/002193470103100401

McKamey, C. (2017). Learning and teaching to care for young people. Child \& Youth Services, 38(3), 209-230. doi:10.1080/0145935X.2017.1297226

Mann-Feder, V. R., \& Litner, B. (2004). A normative re-educative approach to youthwork education: Department of Applied Human Sciences, Concordia University. Child and Youth Care Forum, 33(4), 275-286. doi:10.1023/B:CCAR.0000035377.36618.d9

Nagro, S. A., Shepherd, K. G., West, J. E., \& Nagy, S. J. (2019). Activating policy and advocacy skills: A strategy for tomorrow's special education leaders. The Journal of Special Education, 53(2), 67-75. doi:10.1177/0022466918800705

Pagana, K. D. (2013). Ride to the top with a good elevator speech. American Nurse Today, 8(3), $14-16$.

Peltzer, J. N., Teel, C. S., Frank-Ragan, E., \& Nelson-Brantley, H. V. (2016). Strategies for building advocacy skills among undergraduate and graduate nursing students [Educational innovations]. Journal of Nursing Education, 55(3), 177-181. doi:10.3928/01484834$\underline{20160216-11}$

Pon, G., Gosine, K., \& Phillips, D. (2011). Immediate response: Addressing anti-Native and antiBlack racism in child welfare. International Journal of Child, Youth and Family Studies, 2(34), 385-409. doi:10.18357/ijcyfs23/420117763

Ramirez Stege, A. M., Brockberg, D., \& Hoyt, W. T. (2017). Advocating for advocacy: An exploratory survey on student advocacy skills and training in counselling psychology.

Training and Education in Professional Psychology, 11(3), 190-197. doi:10.1037/tep0000158

Saavedra, A., \& Opfer, V. (2012). Learning 21st-century skills requires 21st-century teaching. Phi Delta Kappan, 94(2), 8-13. doi:10.1177/003172171209400203

Saldaña, J. (2016). The coding manual for qualitative researchers (3rd ed.). Sage.

Sanrud, H., \& Ranahan, P. (2012). Pedagogical encounters of the case-based kind. International Journal of Child, Youth and Family Studies, 3(2-3), 234-247. doi:10.18357/ijcyfs32$\underline{3201210868}$

Saraceno, J. (2012). Mapping whiteness and coloniality in the human service field: Possibilities for a praxis of social justice in child and youth care. International Journal of Child, Youth and Family Studies, 3(2-3), 248-271. doi:10.18357/ijcyfs32-3201210869 
International Journal of Child, Youth and Family Studies (2020) 11(3): 108-125

Simpson, D. (2016). "Going up?" A sport psychology consultant's guide to the elevator speech. Journal of Sport Psychology in Action, 7(2), 109-120. doi:10.1080/21520704.2016.1182091

Simpson, L. B. (2014). Land as pedagogy: Nishnaabeg intelligence and rebellious transformation. Decolonization: Indigeneity, Education \& Society, 3(3), 1-25.

Skott-Myhre, H. (2006). Radical youth work: Becoming visible. Child and Youth Care Forum, 35(3), 219-229. doi:10.1007/s10566-006-9010-2

Sperling, R. A., Howard, B. C., Staley, R., \& DuBois, N. (2010). Metacognition and selfregulated learning constructs. Educational Research and Evaluation, 10(2), 117-139. doi:10.1076/edre.10.2.117.27905

Tindowen, D. J. C., Bassig, J. M., \& Cagurangan, J-A. (2017). Twenty-first-century skills of alternative learning system learners. Sage Open, 7(3), 1-8. doi:10.1177/2158244017726116

Truth and Reconciliation Commission of Canada. (2015). Honouring the Truth,

Reconciling the Future: Summary of the Final Report of the Truth and Reconciliation Commission of Canada. Government of Canada. http://nctr.ca/reports.php

United Nations. (1989). Convention on the rights of the child. https://www.ohchr.org/en/professionalinterest/pages/crc.aspx

Vahid, A. (2017). Understanding the role of likeability in the peer assessments of university students' oral presentation skills: A latent variable approach. Language Assessment Quarterly, 14(4), 398-419. doi:10.1080/15434303.2017.1393820

VanderVen, K. (1993). Advancing child and youth care: A model for integrating theory and practice through connecting education, training and the service system. Child and Youth Care Forum, 22(4), 263-284. doi:10.1007/BF00756952

Vitielo, M. (2015). Teaching oral advocacy: Creating more opportunities for an essential skill. Seton Hall Law Review, 45(4), 1031-1048.

Yoon, J-S. (2012). Courageous conversations in child and youth care: Nothing lost in the telling. International Journal of Child, Youth and Family Studies, 3(2-3), 164-186. doi:10.18357/ijcyfs32-3201210864

White, J. (2007). Knowing, doing and being in context: A praxis-oriented approach to child and youth care. Child and Youth Care Forum, 36(5-6), 225-244. doi:10.1007/s10566-007-9043-1 
International Journal of Child, Youth and Family Studies (2020) 11(3): 108-125

\section{Biographies}

Johanne Jean-Pierre PhD is an Assistant Professor in the School of Child and Youth Care at Ryerson University. She holds a doctoral degree in sociology from McMaster University and conducts bilingual research projects in the fields of sociology of education and child and youth studies. Her current research program explores post-secondary trajectories and experiences, alternative school discipline practices, and child and youth care pedagogy. Her research focuses on the social-cultural dynamics that can inform promising policies and practices to work with refugee and immigrant youth, African Canadian communities, and linguistic minorities such as Francophone minority communities.

Sabrin Hassan holds a master's degree of Social Work (MSW) from the University of Toronto with a specialization in mental health and health, a bachelor's degree of arts in Child and Youth Care from Ryerson University, and a college diploma in Child and Youth Work from George Brown College. Her research interests include culturally responsive approaches with a focus on practice in Black communities.

Asha Sturge is working towards her bachelor's degree in Child and Youth Care at Ryerson University. She holds a college diploma in Child and Youth Care from Humber College.

Kiaras Gharabaghi $\mathrm{PhD}$ is a Professor in the School of Child and Youth Care at Ryerson University. His core research and professional activities are focused on the ongoing evolution of child and youth care practice in Canada and globally, residential care and treatment, system/organizational change, and social innovation and entrepreneurship. His most recent book is A Hard Place to Call Home: A Canadian Perspective (Canadian Scholars Press, 2019).

Megan Lewis is a young Kanien'kehá:ka woman from Tyendinaga Mohawk Territory, currently residing in Tkaronto, Ontario. She holds a Master of Arts in Public Policy and Administration and a bachelor's degree in Child and Youth Care. She has developed a passion for the advocacy of Indigenous people and communities through education. Over the years she has held various roles both on the front line in community organizations and in the federal government, and she continues to strive to make connections between policy and practice in her current role as the Policy and Research Manager at Canadian Roots Exchange (CRE).

Jonathan Bailey is working towards a Master of Arts in Counselling Psychology at Yorkville University with a specialization in child and family therapy. He holds a bachelor's degree in Child and Youth Care from Ryerson University and a college diploma in Child and Youth Work from George Brown College. Jonathan's research interests include the effects of parenting support on children's mental health and the social determinants of health that impact the quality of life of parents and children.

Melanie Panitch DSW is an Associate Professor and the Executive Director, Office of Social Innovation at Ryerson University. She was the founding Director of the School of Disability Studies. Throughout her career she has been an activist, advocate, researcher, and educator, with strong roots in the disability rights movement and broad international experience. She has been central to embedding social innovation curriculum, teaching core courses in the minor in Social Innovation, and fostering international student engagement for social innovation. Her research, published as Disability, Mothers and Organization: Accidental Activists (Routledge, 2008), is a gendered history of activist mothering in the Canadian Association for Community Living. 